\title{
Beetles (Coleoptera) on plantations of selected herbs in south-east Poland
}

\author{
Chrząszcze (Coleoptera) na plantacjach wybranych ziół \\ w południowo-wschodniej Polsce
}

\author{
Zbigniew Czerniakowski ${ }^{1 *}$, Łukasz Zadorożny²
}

\section{Summary}

In the years 2012-2019 observations were made of entomofauna found in the cultivars of purple coneflower [Echinacea purpurea (L.) Moench], lovage (Levisticum officinale W.D.J. Koch), garden angelica (Angelica archangelica L.) and chinese rhubarb (Rheum palmatum L.). The insects from the order of the Coleoptera beetles were the most numerous group. Beetles clearly dominated the cultivation of R. palmatum, where they constituted $87.6 \%$ of all insects caught, and the phytophages - flea beetles from Chaetocnema genus and Gastrophysa viridula (De Geer) turned out to be the most common species. In addition, during the harvest in 2016, severe damage to the roots of $L$. officinale by larvae of a previously unspecified species was noted. In 2018, the first wilting of lovage plants during vegetation was noted, and root infestation during the harvest period reached 100\%. Barber's traps set up in 2019 confirmed that the species responsible for the losses is Liophloeus tessulatus (O.F. Müller).

Key words: medicinal plants pests, harmful insects

\section{Streszczenie}

W latach 2012-2019 prowadzono obserwacje entomofauny występującej w uprawach jeżówki purpurowej [Echinacea purpurea (L.) Moench], lubczyku ogrodowego (Levisticum officinale W.D.J. Koch), arcydzięgla litwor (Angelica archangelica L.) i rzewienia dłoniastego (Rheum palmatum L). Najliczniej odławianą grupę stanowiły owady z rzędu chrząszcze (Coleoptera). Chrząszcze w zdecydowany sposób dominowały w uprawie $R$. palmatum, gdzie stanowiły aż $87,6 \%$ wszystkich odłowionych owadów, a gatunkami najliczniej występującymi okazały się fitofagi - przedstawiciele rodzaju Chaetocnema oraz Gastrophysa viridula (De Geer). Ponadto podczas zbioru w roku 2016 zauważono silne uszkodzenie korzeni L. officinale przez larwy nie oznaczonego wcześniej gatunku. W roku 2018 odnotowano pierwsze więdnięcia roślin lubczyku w czasie wegetacji, a porażenie korzeni w okresie zbioru sięgnęło 100\%. Założone w 2019 roku pułapki Barbera potwierdziły, że gatunkiem odpowiedzialnym za straty jest Liophloeus tessulatus (O.F. Müller).

Słowa kluczowe: szkodniki roślin leczniczych, owady szkodliwe

\footnotetext{
${ }^{1}$ Uniwersytet Rzeszowski

Kolegium Nauk Przyrodniczych, Zakład Agroekologii

Ćwiklińskiej 2, 35-601 Rzeszów

${ }^{2}$ Urząd Statystyczny w Rzeszowie

Jana III Sobieskiego 10, 35-959 Rzeszów

*corresponding author: haazi@wp.pl

ORCID: 0000-0002-9483-0448
} 


\section{Wstęp / Introduction}

Wprawdzie areał uprawy roślin zielarskich $\mathrm{w}$ latach 2005-2012 na terenie Polski uległ niewielkiemu zmniejszeniu (Olewnicki i wsp. 2015), to jednak w ostatnich latach zaobserwować można ponowny wzrost zainteresowania rolników tymi uprawami. Tradycyjnie największa powierzchnia plantacji ziół znajduje się w województwach: lubelskim, kujawsko-pomorskim, mazowieckim, świętokrzyskim i wielkopolskim (Newerli-Guz 2016). Podkarpacie na tle wymienionych regionów nie wypada zbyt imponująco, są tu jednak szczególnie dobre warunki do uprawy cennych dla przemysłu farmaceutycznego roślin korzeniowych, takich jak: arcydzięgiel litwor, jeżówka purpurowa, lubczyk ogrodowy i prawoślaz lekarski (Bilek 2019). Znaleźć można także uprawy bardzo ciekawej rośliny jaką jest rzewień dłoniasty.

Obserwowany w ostatnich latach wzrost zainteresowania zielarstwem i ziołolecznictwem, a także stale rosnący popyt na produkty pochodzenia roślinnego wymagają zwiększenia plonów ziół przy jednoczesnym zachowaniu szczególnych rygorów dotyczących jakości surowca (Bilek 2019). Jednym z warunków, jaki musi być bezwzględnie spełniony jest odpowiednio wczesne rozpoznanie i prognozowanie zagrożeń związanych z wystąpieniem agrofagów, albowiem stawiane wymagania przez skupy oraz firmy przetwórcze często uniemożliwiają plantatorom stosowanie chemicznych środków ochrony roślin w uprawach roślin zielarskich. Wynika to z późniejszego przeznaczenia surowca, który wykorzystywany jest między innymi $\mathrm{w}$ przemyśle farmaceutycznym, kosmetycznym, czy gastronomii. Ze względu na fakt, że obecność fitofagów w uprawach zielarskich położonych w południowo-wschodniej Polsce stanowi poważny problem dla producentów ziół, podjęto próbę rozpoznania struktury ilościowo-jakościowej entomofauny występującej na uprawianych w tym regionie gatunkach roślin zielarskich.

\section{Materiały i metody / Materials and methods}

Badania terenowe prowadzono w latach 2012-2019 na plantacjach położonych w miejscowości Markowa (UTM: EA94), która jest jednym z tradycyjnych ośrodków uprawy roślin zielarskich na Podkarpaciu. Szczegółowymi obserwacjami objęto uprawy 4 roślin stanowiących surowiec dla przemysłu farmaceutycznego: jeżówki purpurowej [Echinacea purpurea (L.) Moench] (3 plantacje o powierzchni 0,25-0,30 ha), lubczyku ogrodowego (Levisticum officinale W.D.J. Koch) (4 plantacje o powierzchni 0,28-1,5 ha), arcydzięgla litwor (Angelica archangelica L.) (2 plantacje o powierzchni $0,56-0,60$ ha) i rzewienia dłoniastego (Rheum palmatum L.) (3 plantacje o powierzchni $0,46-0,85$ ha). W latach 2012-2015 odłowy entomofauny prowadzono metodą czerpakową ( 25 zagarnięć czerpakiem wzdłuż przekątnej plantacji) od końca kwietnia do końca października, w odstępach 1-2-tygodniowych. Zebrany materiał opracowano za pomocą ogólnie przyjętych wskaźników zoocenotycznych: liczebności względnej, frekwencji i dominacji (Czachorowski 2004).

Otrzymane wyniki sprawdzono za pomocą testu $G$ z poprawką Williamsa. W hipotezie zerowej założono, że rozkład łączny jest $\mathrm{w}$ pełni określony przez rozkłady brzegowe. Podstawą tworzenia tego testu jest tablica liczności o $r$ wierszach i $k$ kolumnach. Test $G$ przyjęto w postaci:

$$
G=2 \sum_{i=1}^{r} \sum_{j=1}^{k} n_{i j} \ln \frac{n_{i j}}{n_{i_{j}}}
$$

gdzie:

$n_{i j}$ - oznacza liczbę elementów próby,

$$
n_{i}=\sum_{j=1}^{k} n_{i j} \text { oraz } n_{j}=\sum_{i=1}^{r} n_{i j}, \hat{n}_{i j}=\frac{n_{i} n_{j}}{n}
$$

ma rozkład $\chi^{2}$ o $(r-1)(k-1)$ stopniach swobody.

W przypadku, gdy w pewnych komórkach tabeli kontyngencji występuje mała liczebność oczekiwana stosuje się poprawkę Williamsa. Statystykę testową dzieli się przez czynnik:

$$
G=1+\frac{a^{2}-1}{6 n(r-1)(k-1)},
$$

gdzie, $a$ - to liczba kategorii.

Test $G$ z poprawką Williamsa zastosowano w związku z małymi (zerowymi) wartościami $\mathrm{z}$ niektórych prób (McDonald 2014).

Równolegle do 2019 roku prowadzono lustrację wszystkich plantacji, a w ostatnim roku, w uprawie lubczyku, założono pułapki Barbera. Pięć pułapek Barbera umieszczono po przekątnej plantacji o powierzchni 0,5 ha w połowie kwietnia (13.04.2019 r.). Zawartość pułapek wybierano raz w tygodniu do końca pierwszej dekady sierpnia (11.08.2019 r.). Łącznie przeprowadzono 14 prób.

\section{Wyniki i dyskusja / Results and discussion}

Podczas prowadzonego czerpakowania z wymienionych wyżej upraw odłowiono łącznie 14372 imagines owadów należących do 6 rzędów. Analiza statystyczna wykazała (na poziomie $\mathrm{p}<0,0001$ ) istotne różnice wskaźników zoocenotycznych pomiędzy poszczególnymi uprawami, dotyczące zarówno rzędów (tab. 1), jaki i rodzin (tab. 3) występujących owadów.

Najliczniej odławianą grupę stanowiły owady z rzędu chrząszcze (Coleoptera), reprezentowane przez 9255 osobników (64,4\% wszystkich odłowionych owadów). Chrząszcze w zdecydowany sposób dominowały w uprawie R. palmatum (rys. 1), gdzie w latach 2012-2015 odłowiono łącznie 7328 osobników z tego rzędu. W uprawie rze- 
Tabela 1. Liczebność owadów odłowionych w obserwowanych uprawach ziół w latach 2012-2015

Table 1. The number of insects caught in the observed herbs crops in 2012-2015

\begin{tabular}{|c|c|c|c|c|c|}
\hline \multirow{2}{*}{$\begin{array}{l}\text { Rząd } \\
\text { Order }\end{array}$} & \multicolumn{4}{|c|}{ Liczba osobników* - Number of individuals } & \multirow{2}{*}{$\Sigma$} \\
\hline & Rheum palmatum & Levisticum officinale & Angelica archangelica & Echinacea purpurea & \\
\hline Coleoptera & 7328 & 1044 & 408 & 475 & 9255 \\
\hline Dermaptera & 56 & 0 & 131 & 14 & 201 \\
\hline Hemiptera & 748 & 1944 & 1510 & 336 & 4538 \\
\hline Hymenoptera & 59 & 9 & 1 & 0 & 69 \\
\hline Mecoptera & 21 & 0 & 0 & 0 & 21 \\
\hline Neuroptera & 149 & 72 & 55 & 12 & 288 \\
\hline$\Sigma$ & 8361 & 3069 & 2105 & 837 & 14372 \\
\hline
\end{tabular}

*różnice istotne na poziomie $\mathrm{p}<0,0001$ wykazane testem $G$ z poprawką Williamsa - significant differences at $\mathrm{p}<0.0001$ demonstrated by $G$ test with Williams correction

Tabela 2. Chrząszcze (Coleoptera) odłowione na rzewieniu dłoniastym (Rheum palmatum L.) w latach 2012-2015

Table 2. Beetles (Coleoptera) caught on the Chinese rhubarb (Rheum palmatum L.) in 2012-2015

\begin{tabular}{|c|c|c|c|c|c|}
\hline $\begin{array}{l}\text { Rodzina } \\
\text { Family }\end{array}$ & $\begin{array}{l}\text { Gatunek } \\
\text { Species }\end{array}$ & \begin{tabular}{|c|} 
Liczba osobników \\
[szt.] \\
Number of specimens \\
{$[\mathrm{pcs}]$}
\end{tabular} & $\begin{array}{c}\text { Liczebność } \\
\text { względna } \\
\text { Relative numbers } \\
{[\%]}\end{array}$ & $\begin{array}{c}\text { Frekwencja } \\
\text { Frequency } \\
{[\%]}\end{array}$ & $\begin{array}{l}\text { Dominacja } \\
\text { Domination }\end{array}$ \\
\hline 1 & 2 & 3 & 4 & 5 & 6 \\
\hline \multirow{2}{*}{ Brentidae } & Apion frumentarium $\mathrm{L}$. & 62 & 0,7 & $38,9-53,3$ & subrecedent \\
\hline & Perapion violaceum Kirby & 47 & 0,6 & $13,3-44,4$ & subrecedent \\
\hline \multirow{4}{*}{ Cantharidae } & Cantharis fusca $\mathrm{L}$. & 90 & 1,1 & $30,0-50,0$ & recedent \\
\hline & Cantharis livida $\mathrm{L}$. & 63 & 0,8 & $38,9-53,3$ & subrecedent \\
\hline & Cantharis rustica Fallen & 5 & 0,1 & $5,6-13,3$ & subrecedent \\
\hline & Rhagonycha fulva Scop. & 99 & 1,2 & $6,7-53,3$ & recedent \\
\hline \multirow{3}{*}{ Carabidae } & Calathus melanocephalus L. & 3 & 0,04 & $5,6-13,3$ & subrecedent \\
\hline & Demetrias atricapillus $\mathrm{L}$. & 42 & 0,5 & $26,7-44,4$ & subrecedent \\
\hline & Drypta dentata Rossi & 3 & 0,04 & $6,7-11,1$ & subrecedent \\
\hline Cerambycidae & Strangalia attenuata L. & 2 & 0,02 & 5,6 & subrecedent \\
\hline \multirow{6}{*}{ Chrysomelidae } & Chaetocnema sp. & 3602 & 43,1 & $93,3-100$ & eudominant \\
\hline & Gastrophysa polygoni $\mathrm{L}$. & 48 & 0,6 & $20,0-46,7$ & subrecedent \\
\hline & Gastrophysa viridula De Geer & 2056 & 24,6 & $86,7-100$ & eudominant \\
\hline & Oulema obscura Steph. & 8 & 0,1 & 26,7 & subrecedent \\
\hline & Oulema melanopus L. & 11 & 0,1 & $6,7-22,2$ & subrecedent \\
\hline & Phyllotreta undulata Kutschera & 3 & 0,04 & $6,7-13,3$ & subrecedent \\
\hline \multirow{6}{*}{ Coccinellidae } & Adalia bipunctata $\mathrm{L}$. & 19 & 0,2 & $13,3-27,8$ & subrecedent \\
\hline & Adonia variegata Goeze & 4 & 0,05 & $5,6-13,3$ & subrecedent \\
\hline & Coccinella septempunctata $\mathrm{L}$. & 109 & 1,3 & $44,4-70,0$ & recedent \\
\hline & Harmonia axyridis Pallas & 323 & 3,9 & $55,6-73,3$ & subdominant \\
\hline & Propylea quatuordecimpunctata $\mathrm{L}$. & 51 & 0,6 & $40,0-60,0$ & subrecedent \\
\hline & Stethorus punctillum Herbst & 116 & 1,4 & $44,4-70,0$ & recedent \\
\hline \multirow{6}{*}{ Curculionidae } & Anthonomus rectirostris L. & 1 & 0,01 & 5,6 & subrecedent \\
\hline & Chlorophanus viridis $\mathrm{L}$. & 4 & 0,05 & 16,7 & subrecedent \\
\hline & Lixus bardanae Fab. & 4 & 0,05 & 30,0 & subrecedent \\
\hline & Rhinoncus pericarpius L. & 39 & 0,5 & $30,0-46,7$ & subrecedent \\
\hline & Sitona lateralis Gyll. & 3 & 0,04 & $6,7-11,1$ & subrecedent \\
\hline & Polydrusus inustus Germar. & 3 & 0,04 & 11,1 & subrecedent \\
\hline
\end{tabular}


Tabela 2. Chrząszcze (Coleoptera) odłowione na rzewieniu dłoniastym (Rheum palmatum L.) w latach 2012-2015 - cd.

Table 2. Beetles (Coleoptera) caught on the Chinese rhubarb (Rheum palmatum L.) in 2012-2015 - continued

\begin{tabular}{c|l|c|c|c|c}
\hline \multicolumn{1}{c|}{1} & \multicolumn{1}{|c|}{2} & 3 & 4 & 5 & 6 \\
\hline \multirow{4}{*}{ Elateridae } & Adrastus pallens Fab. & 82 & 1,0 & $26,7-53,3$ & subrecedent \\
\cline { 2 - 6 } & Agriotes sputator L. & 10 & 0,1 & $11,1-20,0$ & subrecedent \\
\cline { 2 - 6 } & Agrypnus murinus L. & 32 & 0,4 & $30,0-33,3$ & subrecedent \\
\cline { 2 - 6 } & Hemicrepidius niger L. & 50 & 0,6 & $20,0-33,3$ & subrecedent \\
\hline Latridiidae & - & 219 & 2,6 & $50,0-80,0$ & subdominant \\
\hline Melyridae & Anthocomus rufus Herbst & 1 & 0,01 & 6,7 & subrecedent \\
\hline Nitidulidae & - & 66 & 0,8 & $33,3-50,0$ & subrecedent \\
\hline Phalacridae & Olibrus bicolor Fab. & 27 & 0,3 & $13,3-38,9$ & subrecedent \\
\hline Staphylinidae & Tachyporus hypnorum Fab. & 21 & 87,6 & $16,7-20,0$ & subrecedent \\
\hline Chrząszcze razem - Total beetles & 7328 & 12,4 & - & - \\
\hline Inne rzędy - Other orders & 1033 & 100,0 & - & - \\
\hline Razem - Total & & 8361 & & - \\
\hline
\end{tabular}

Tabela 3. Najliczniejsze rodziny chrząszczy odławianych w obserwowanych uprawach ziół w latach 2012-2015

Table 3. The most numerous families of beetles caught in the observed herbs in 2012-2015

\begin{tabular}{|c|c|c|c|c|c|}
\hline \multirow{2}{*}{$\begin{array}{c}\text { Rodzina } \\
\text { Family }\end{array}$} & \multicolumn{4}{|c|}{ Liczba osobników* - Number of individuals } & \multirow{2}{*}{$\Sigma$} \\
\hline & Rheum palmatum & Levisticum officinale & Angelica archangelica & Echinacea purpurea & \\
\hline Chrysomelidae & 5728 & 28 & 13 & 5 & 5774 \\
\hline Coccinellidae & 622 & 210 & 79 & 7 & 918 \\
\hline Latridiidae & 219 & 157 & 44 & 27 & 447 \\
\hline Nitidulidae & 66 & 482 & 216 & 388 & 1152 \\
\hline Cantharidae & 257 & 24 & 20 & 0 & 301 \\
\hline Curculionidae & 54 & 65 & 16 & 30 & 165 \\
\hline Elateridae & 174 & 61 & 17 & 10 & 262 \\
\hline Inne - Other & 208 & 17 & 3 & 8 & 236 \\
\hline$\Sigma$ & 7328 & 1044 & 408 & 475 & 9255 \\
\hline
\end{tabular}

*różnice istotne na poziomie $\mathrm{p}<0,0001$ wykazane testem $G$ z poprawką Williamsa - significant differences at $\mathrm{p}<0.0001$ demonstrated by $G$ test with Williams correction

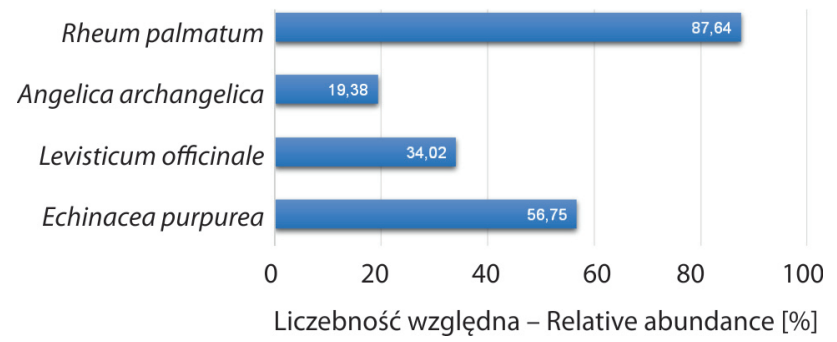

Rys. 1. Liczebność względna [\%] chrząszczy odłowionych w obserwowanych uprawach roślin zielarskich w latach 2012-2015

Fig. 1. Relative abundance [\%] of beetles collected in observed herbal crops in in 2012-2015

wienia stanowiły one aż $87,6 \%$ wszystkich odłowionych owadów. Gatunkami najliczniej występującymi okazały się fitofagi, dla których roślinami żywicielskimi są rdestowate (Polygonaceae). Były to: pchełka burakowa (Chaetocnema concinna Marsh.) i Chaetocnema laevicollis (Thoms.), których odłowiono łącznie 3602 okazy oraz kałdunica zielonka (Gastrophysa viridula De Geer) reprezentowana przez 2056 osobników. Frekwencja wymienionych gatunków sięgała w poszczególnych latach $100 \%$, co świadczy o wyjątkowej stałości ich występowania w uprawie $R$. palmatum (tab. 2). Liczebność Ch. concinna i Ch. laevicollis przedstawiono łącznie w tabeli 2. z uwagi na bardzo duże podobieństwo obu gatunków (Warchałowski 2003; Lesage i Majka 2010). Przeprowadzona analiza aparatów kopulacyjnych wskazuje na przewagę $C h$. concinna.

Pchełka burakowa (Ch. concinna) jest gatunkiem powszechnie występującym na stanowiskach naturalnych oraz użytkach zielonych (Lesage i Majka 2010; Frank i wsp. 2012; van Klink i wsp. 2016). Wymieniana jest także 
jako szkodnik buraka, gryki, szczawiu, a nawet truskawki (Bukejs 2008). Występuje w Polsce przez cały rok na stanowiskach roślinności synantropijnej oraz ruderalnej, przy czym ściśle związana jest $\mathrm{z}$ roślinami z rodziny rdestowatych i komosowatych (Warchałowski 1998). Jak podaje Burakowski i wsp. (1991) roślinami żywicielskimi chrząszczy tego gatunku mogą być: rdest ptasi (Polygonum aviculare L.), szczaw (Rumex sp.), tatarka (Fagopyrum tataricum Gaertn.) oraz rabarbar uprawny (Rheum rhaponticum L.). Na możliwość występowania Ch. concinna na rabarbarze uprawnym wskazuje także Szwejda i Rogowska (2004). Liczne i stałe występowanie tego gatunku na obserwowanych stanowiskach rzewienia nie skutkowało silnym uszkodzeniem tej rośliny. Zaobserwowane dorosłe chrząszcze wygryzały w liściach $R$. palmatum jedynie drobne okienka, które biorąc pod uwagę wielkość liści, nie powinny w znaczący sposób zmniejszyć powierzchni asymilacyjnej. Zaznaczyć należy jednak, że larwy Chaetocnema (których nie stwierdzono podczas prowadzonych obserwacji) żerują na korzeniach roślin, co może mieć wpływ na ich wzrost (Bieńkowski 2004).

Szczególnie duże uszkodzenia liści $R$. palmatum obserwowano w przypadku wystąpienia chrząszczy oraz larw G. viridula (fot. 1). Według Warchałowskiego (1994) gatunek ten związany jest przede wszystkim z różnymi gatunkami szczawiu, a jego obecność na uprawnych gatunkach rabarbaru jest niejasna. Szwejda i Rogowska (2004) uznali ten gatunek za subrecedenta na plantacji rabarbaru. Tymczasem w okresie prowadzonych obserwacji frekwencja chrząszczy kałdunicy zielonki na $R$. palmatum sięgała 100\% (w roku 2012 i 2014), a gęstość przekraczała 42 osobniki na odłów (w 2014 r.) (tab. 2). Zarówno imagines, jak i larwy żerowały na liściach rzewienia w sposób opisany wcześniej na roślinach z rodzaju Rumex (Smith i Whittaker 1980; Burakowski i wsp. 1990; Piesik i Wenda-Piesik 2005) doprowadzając niekiedy do gołożeru. Szczególnie duża

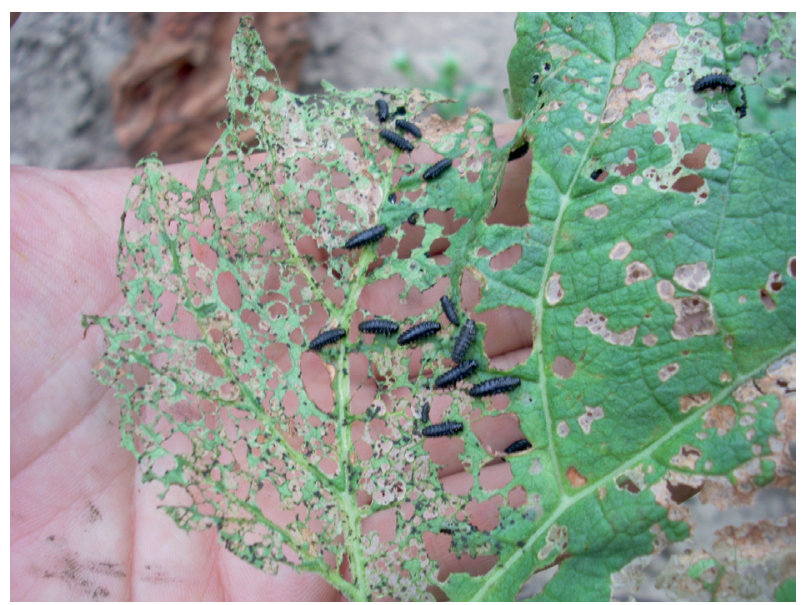

Fot. 1. Uszkodzenia liści rzewienia dłoniastego spowodowane przez chrzaszcze i larwy Gastrophysa viridula (De Geer)

Phot. 1. Chinese rhubarb leaf damage caused by Gastrophysa viridula (De Geer) beetles and larvae liczba larw, uwarunkowana zapewne w znacznym stopniu ich odpornością na pasożyty i drapieżniki (Burse i wsp. 2007, 2009; Boland 2015), skutkowała w niektóre lata poważnymi uszkodzeniami, zwłaszcza młodych roślin (fot. 2).

W uprawie pozostałych gatunków roślin chrząszcze występowały mniej licznie, a gatunkami najczęściej odławianymi byli przedstawiciele rodzin Cantharidae, Nitidulidae i Latridiidae nie powodujący uszkodzeń obserwowanych roślin. Stosunkowo wysoka liczebność

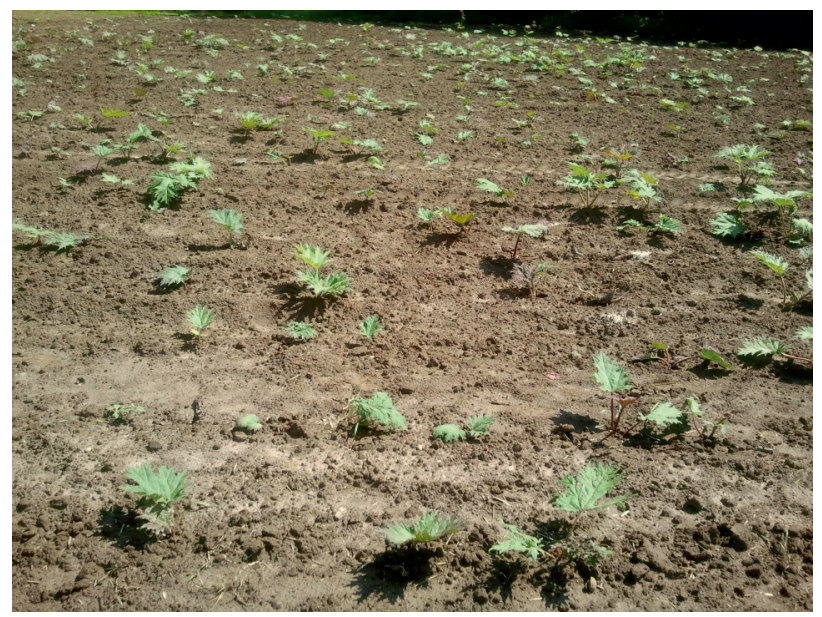

Fot. 2. Uprawa rzewienia dłoniastego zaatakowana przez $G a-$ strophysa viridula (1 czerwca 2015 roku)

Phot. 2. Chinese rhubarb cultivation attacked by Gastrophysa viridula (June 1, 2015)

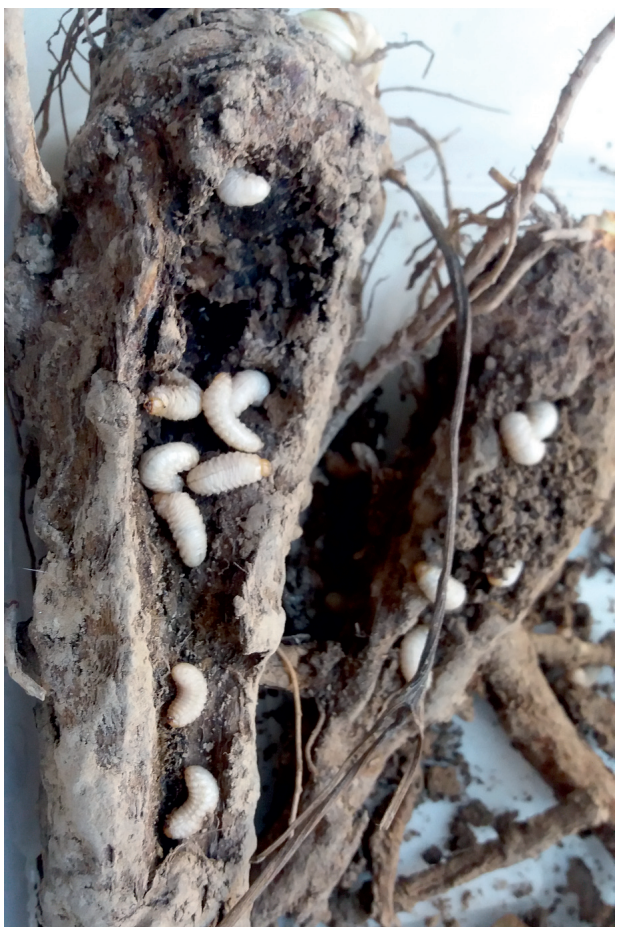

Fot. 3. Larwy Liophloeus tessulatus żerujące na korzeniu lubczyku ogrodowego

Phot. 3. Liophloeus tessulatus larvae feeding on the lovage root 
przedstawicieli rodziny biedronkowatych (Coccinellidae) wynikała zapewne z obecności kolonii mszyc (zwłaszcza na R. palmatum i L. officinale) (tab. 3).

W roku 2016 podczas zbioru zauważono znaczne ilości larw nieznanego gatunku ryjkowca oraz silne uszkodzenie korzeni L. officinale (fot. 3). W roku 2018 odnotowano pierwsze więdnięcia roślin w czasie wegetacji, a porażenie korzeni w okresie zbioru sięgnęło 100\%. Założone w 2019 r. pułapki Barbera oraz hodowla larw potwierdziły przypuszczenie, że gatunkiem odpowiedzialnym za straty jest szkodnik lubczyku - oskardzik korzeniowy (Liophloeus tessulatus O.F. Müller). Jak podają Czerniakowski i Czerniakowski (2012) należy on do typowych szkodników lubczyku. Nieodławiane wcześniej czerpakiem imagines występowały w pułapkach Barbera stosunkowo krótko (maj-czerwiec) i w przeciwieństwie do larw nie powodowały zauważalnych uszkodzeń na roślinach.

\section{Wnioski / Conclusions}

1. Chrząszcze (Coleoptera) na obserwowanych plantacjach roślin zielarskich stanowiły najliczniej odławianą grupę owadów.

2. Wśród oznaczonych osobników zidentyfikowano dwa gatunki, które powodowały znaczące uszkodzenia roślin. Były to: imagines i larwy kałdunicy zielonki (G. viridula) w uprawie rzewienia ( $R$. palmatum) oraz larwy oskardzika korzeniowego (L. tessulatus) w uprawie lubczyku (L. officinale).

3. Na plantacjach rzewienia dłoniastego i lubczyku ogrodowego niezbędne jest prowadzenie systematycznych lustracji w celu kontroli liczebności kałdunicy zielonki oraz oskardzika korzeniowego.

\section{Literatura / References}

Bieńkowski A.O. 2004. Leaf-Beetles (Coleoptera: Chrysomelidae) of Eastern Europe. New key to subfamilies, genera and species. Mikron-print, Moscow, 278 ss. ISBN 978-593-497-02-47.

Bilek M. 2019. Uprawa i pozyskiwanie roślin leczniczych w świetle wymogów systemu GACP. Podkarpackie Wiadomości Rolnicze 12: $30-34$.

Boland W. 2015. Sequestration of plant-derived glycosides by leaf beetles: A model system for evolution and adaptation. Perspectives in Science 6: 38-48. DOI: 10.1016/j.pisc.2015.06.001

Bukejs A. 2008. To the knowledge of flea beetles (Coleoptera: Chrysomelidae: Alticinae) in the fauna of Latvia. 1. Genus Chaetocnema Stephens, 1831. Acta Zoologica Lituanica 18 (3): 191-197. DOI: 10.2478/v10043-008-0029-5

Burakowski B., Mroczkowski M., Stefańska J. 1990. Katalog Fauny Polski 23 (16). Chrząszcze - Coleoptera. Stonkowate - Chrysomelidae, Część 1, 279 ss.

Burakowski B., Mroczkowski M., Stefańska J. 1991. Katalog Fauny Polski 23 (17). Chrząszcze - Coleoptera. Stonkowate -Chrysomelidae, Część 2, 226 ss.

Burse A., Frick S., Discher S., Tolzin-Banasch K., Kirsch R., Strauss A., Kunert M., Boland W. 2009. Always being well prepared for defense: the production of deterrents by juvenile Chrysomelina beetles (Chrysomelidae). Phytochemistry 70 (15-16): 1899-1909. DOI: 10.1016/j.phytochem.2009.08.002

Burse A., Schmidt A., Frick S., Kuhn J., Gershenzon J., Boland W. 2007. Iridoid biosynthesis in Chrysomelina larvae: Fat bodyproduces early terpenoid precursors. Insect Biochemistry and Molecular Biology 37 (3): 255-265. DOI: 10.1016/j.ibmb.2006.11.011

Czachorowski S. 2004. Opisywanie biocenozy - zoocenologia, skrypt elektroniczny dla magistrantów. www.uwm.edu.pl/czachor/publik/ pdf-inne/zoocenozy.pdf, 59 ss.

Czerniakowski Z.W., Czerniakowski Z. 2012. Szkodniki ziół. Mitel, Rzeszów, 350 ss.

Frank T., Aeschbacher S., Zaller J.G. 2012. Habitat age affects beetle diversity in wildflower areas. Agriculture, Ecosystems and Environment 152: 21-26. DOI: 10.1016/j.agee.2012.01.027

Lesage L., Majka C.G. 2010. Introduced leaf beetles of the Maritime Provinces, 9: Chaetocnema concinna (Marsham, 1802) (Coleoptera: Chrysomelidae). Zootaxa 2610: 27-49. DOI: 10.11646/zootaxa.2610.1.2

McDonald J.H. 2014. Handbook of Biological Statistics (Third ed.). Sparky House Publishing, Baltimore, Maryland, 299 ss.

Newerli-Guz J. 2016. Uprawa roślin zielarskich w Polsce. [The cultivation of herbal plants in Poland]. Roczniki Naukowe Stowarzyszenia Ekonomistów Rolnictwa i Agrobiznesu 18 (3): 268-274.

Olewnicki D., Jabłońska L., Orliński P., Gontar Ł. 2015. Zmiany w krajowej produkcji zielarskiej i wybranych rodzajach przetwórstwa roślin zielarskich w kontekście globalnego wzrostu popytu na te produkty. [Changes in Polish domestic production of herbal plants and in selected types of enterprises that process herbal plants in the context of the global increase in demand for these products]. Zeszyty Naukowe Szkoły Głównej Gospodarstwa Wiejskiego w Warszawie, Problemy Rolnictwa Światowego 15 (30), z. 1: 68-76.

Piesik D., Wenda-Piesik A. 2005. Gastroidea viridula Deg. potential to control mossy sorrel (Rumex confertus Willd.). Journal of Plant Protection Research 45 (2): 63-71.

Smith R.W., Whittaker J.B. 1980. Factors affecting Gastrophysa viridula popularions (Coleoptera: Chrysomelidae) in different habitats. Journal of Animal Ecology 49 (2): 537-548. DOI: 10.2307/4262

Szwejda J., Rogowska M. 2004. Fitofagiczna entomofauna występująca na rabarbarze. [Phytophagous entomofauna occurring on rhubarb]. Progress in Plant Protection/Postępy w Ochronie Roślin 44 (1): 444-451.

van Klink R., Ruifrok J.L., Smit C. 2016. Rewilding with large herbivores: direct effects and edge effects of grazing refuges on plant and invertebrate communities. Agriculture, Ecosystems and Environment 234: 81-97. DOI: 10.1016/j.agee.2016.01.050

Warchałowski A. 1994. Fauna Polski T. 16. Chrysomelidae Cz. 4. Polska Akademia Nauk, Muzeum i Instytut Zoologii, Warszawa, 302 ss. Warchałowski A. 1998. Fauna Polski T. 20. Chrysomelidae Cz. 6. Polska Akademia Nauk, Muzeum i Instytut Zoologii, Warszawa, 292 ss. Warchałowski A. 2003. Chrysomelidae. The leaf-beetles of Europe and Mediterranean area. Natura optima dux Foundation, Warszawa, 600 ss. 